\title{
Environmental Impacts Investigation of Irrigation Projects: Case Study of Kanyonyomba Rice Perimeter in Rwanda
}

\author{
Félicien Majoro ${ }^{1 *}$, Concilie Mukamwambali², Jean D'Amour Uwimana Shumbusho3, \\ Emmanuel Hagenimana ${ }^{1}$ \\ ${ }^{1}$ Department of Civil, Environmental and Geomatics Engineering, College of Science and Technology, University \\ of Rwanda, Kigali, Rwanda \\ ${ }^{2}$ Department of Mathematics, Science and Physical Education, College of Education, University of Rwanda, \\ Kigali, Rwanda \\ ${ }^{3}$ Department of Agriculture and Natural Resources, Nyarugenge District, Kigali City, Rwanda \\ Email: *majoro.felicien@yahoo.fr
}

Received 29 April 2016; accepted 4 June 2016; published 7 June 2016

Copyright (C) 2016 by authors and Scientific Research Publishing Inc.

This work is licensed under the Creative Commons Attribution International License (CC BY).

http://creativecommons.org/licenses/by/4.0/

(c) (i) Open Access

\section{Abstract}

Irrigation is an agricultural practice adopted in Rwanda to fight against poverty by increasing agricultural production as a big sector which occupies a central place in the economy of the country. Once irrigation project is made without taking into account the environmental impacts that may occur, it may fail before the design period or may persist with the excessive generated negative impacts exceeding the targeted objectives. The aim of this study was to investigate environmental impacts of an already implemented irrigation project in Kanyonyomba swamp located in Gatsibo District of Eastern Province of Rwanda in order to quantify the benefits and to increase agricultural production by mitigating negative impacts generated by this project. The Kanyonyomba earth dam has been constructed on Kanyonyomba River in Gatsibo District with a length, a spillway crest width and a reservoir height of $210 \mathrm{~m}, 4 \mathrm{~m}$ and $8.5 \mathrm{~m}$ respectively. The site observations on land, the interviews analysis and water and soil laboratory tests were conducted to assess various environmental impacts. The analysis of the results reveals the presence of positive impacts including increased agricultural space and agricultural production through the introduction of rice cultivation in this medium. However, this project has led to multiple adverse effects in the hosting environment impacts that need to be mitigated including the increased incidence of diseases in the surrounding population and accidents resulting from an increased exposure of people to the dam reservoir. Moderation of soil acidity, the use of the dam reservoir as a water supply source, the provision of boots and gloves to protect farmers from being contaminated by water living microorganisms and the development of impacts monitoring plan are among the "Corresponding author. 
proposed measures in order to mitigate these environmental impacts.

Keywords

Environmental Impact, Kanyonyomba Rice Perimeter, Rwanda

\section{Introduction}

Nowadays, developing countries are facing with various constraints such as demographic explosion, pressure on arable land and natural calamities due to changes in climatic conditions. Thus, some efforts including birth control, protection of the environment as well as agricultural development plans are among the main political slogans envisaged in each country in order to resolve these issues. These countries are characterized by a predominantly agricultural economy where more efforts are oriented and focused on increasing and improving agricultural productivity. Hence, irrigation can generally be considered as an effective way of increasing agricultural production for any developing country like Rwanda [1].

Irrigation may lead to poverty reduction via increased yields, increased cropping areas and higher value either by raising employment; cutting prices in an imperfectly open economy or if there are high transport costs. Yields boosting by irrigation can mean increased food supplies which lead to better nutrition levels. Irrigation can also help to reduce adverse consequences of drought [2]. As irrigation can generate a stable flow of income through increased intensity of cropping, improved yields and more stable yields across seasons and years, it may also augment employment opportunities [3].

Before we begin to assess how irrigation reduces poverty, we need to consider different meanings of poverty and different types of irrigation. The impact of irrigation on poverty may vary and the indicators of poverty need to be chosen. Narrow or one-dimensional indicators include income and nutrition levels while broader measures may include several dimensions such as access to a range of goods and services including health, education, public transport and utilities, ownership of land and other assets, political freedom and human rights [4].

Although large irrigation projects are taken as a useful tool in boosting the economy of developing world, they have negative environmental impacts including waterlogging and salinization of soils, increased incidence of water-borne and water-related diseases, resettlement or changes in the lifestyle of local populations, and increases of agricultural pests and diseases resulting from the elimination of dry season and the creation of a more humid microclimate [5].

The expansion and intensification of agriculture made possible by irrigation has the potential of causing increased erosion, pollution of surface and ground water from agricultural biocides and the deterioration of water quality. The increased nutrients levels in the irrigation and drainage water result in algal blooms, proliferation of aquatic weeds and eutrophication in irrigation canals and downstream waterways [6].

In Rwanda, rice irrigation projects were launched in several marshlands of the country to raise the rural economy and improve the life quality of poor in rural areas through the transfer of technical and financial resources for sustainable rural development. The use of agricultural inputs such as improved seeds, mineral fertilizers and pesticides are among the activities that accompany these measures [1]. It is in this context that an assessment of environmental impacts was conducted in Kanyonyomba rice perimeter located in Gatsibo District, Eastern province of Rwanda.

Irrigation has a considerable economic and social impact. However, some practices compromise short-term sustainability of production systems by irreversibly deteriorating natural environment. Normally the activities carried out for the purpose of social and economic development should not put at risk the environment and natural balances [5]. This is with a view of highlighting the environmental impacts that may be caused by an irrigation project. Figure 1 is showing a part of conveyance system and reservoir formed by constructing an earth dam across Kanyonyomba River.

\section{Study Area}

The marshland of Kanyonyomba in which this rice irrigation system is implemented is located in Eastern Province, in Gatsibo District, in Kiramurazi, Kiziguro, Murambi and Remera Sectors of Eastern Province of Rwanda in 5 kilometers from Kayonza District following main road in the direction towards Kagitumba-Uganda 

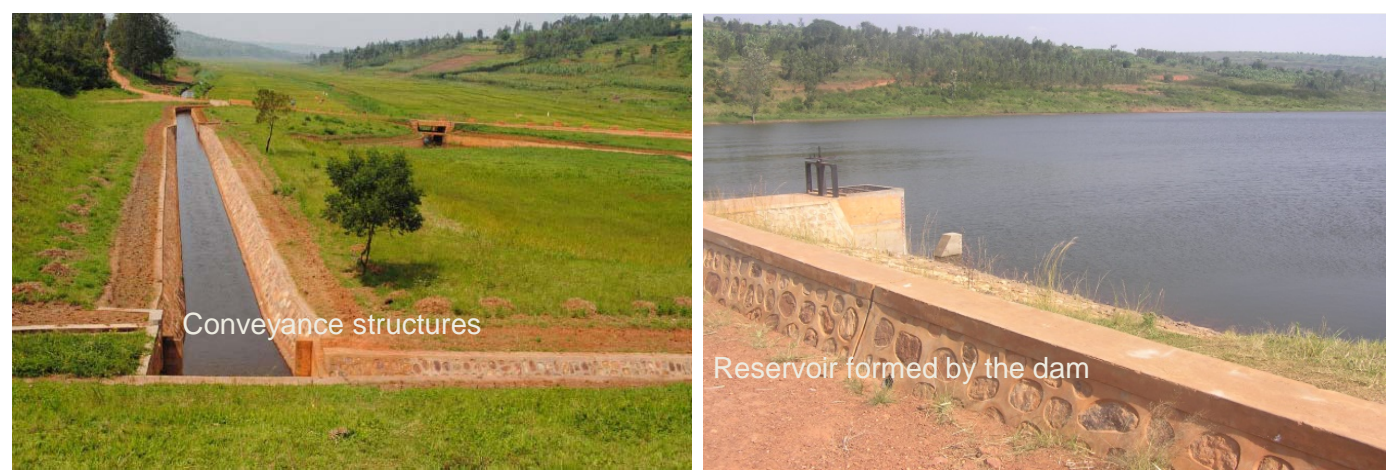

Figure 1. Some hydraulic structures constructed in Kanyonyomba swamp.

border. With a surface area of 710 ha, Kanyonyomba marsh is marked by a large North-South oriented valley. It is drained by the Kanyonyomba River and its tributaries flowing into Lake Muhazi [7]. This marsh has been prepared for the cultivation of rice on an area of about 600 ha. An earth dam reservoir of 595,000 $\mathrm{m}^{3}$ in capacity was built on the river with length, spillway crest width and height of $210 \mathrm{~m}, 4 \mathrm{~m}$ and $8.5 \mathrm{~m}$ respectively. The irrigated perimeter consists of two blocks including the upstream portion located directly below the earth dam and the downstream portion [8].

\section{Data and Methods}

\subsection{Site Visit}

In this study, the site visits were frequently done to Kanyonyomba rice perimeter in order to get more information about the reservoir location, development status of the watershed and irrigated perimeter. Water and soil samples for laboratory tests were also collected at this stage.

\subsection{Survey Methods}

The survey questionnaires were addressed to the swamp rice farmers on how they find the irrigation system implemented for their interest, achievements and constraints as well as for wishes for their prosperity. According to the interviews addressed to site technicians in charge of irrigation, we found that about four hundred and fifty rice farmers exploit the upstream part of the marsh. We interviewed randomly thirty six people working in the swamp, or $8 \%$ of farmers. For a sample to be representative, it is necessary that the ratio is equal to or greater than $0.5 \%$ [9]. Since the problems are not the same upstream and downstream, it has been necessary to have respondents from all sides.

\subsection{Equipment and Soil Sampling Process}

Irrigated perimeter was divided into two blocks for which 10 plots were sampled randomly. Using a marker pen, we spotted successively on an auger at $0-20,20-40 \mathrm{~cm}$ and $40-60 \mathrm{~cm}$ deep. The auger was pressed into the soil to collect soil sample and the depth was determined by the scale of the auger. The soil samples collected at each layer were mixed and homogenized in a container for getting a single representative sample which was put into labeled bag and kept in another container. Thus, for each block, three samples corresponding to three layers were collected.

\subsection{Materials and Water Sampling Process}

During water sampling, one sample was collected at inlet, two samples throughout the irrigation perimeter and one sample at the outlet of the perimeter by using plastic bottles.

\section{Results and Discussion}

\subsection{Observation on the State of the Site Location}

Water reservoir used in irrigation system of Kanyonyomba marshland was formed by constructing an earth dam 
with length, spillway crest width and height of $210 \mathrm{~m}, 4 \mathrm{~m}$ and $8.5 \mathrm{~m}$ respectively across Kanyonyomba River and its tributaries. During the rainy season, runoff from watershed fill dam reservoir. That's why a side rubble lined channel spillway was provided at the top of the dam to pass safely the overflows. The water from the dam has a greenish color and odor of decay. The watershed was not protected against erosion. Throughout the valley, there is a growing form of savannah with some scattered shrub species and isolated eucalyptus micro afforestation. The rice perimeter is divided into small plots of $4 \mathrm{~m}$ by $10 \mathrm{~m}$ and fed by the tertiary canals. These tertiary channels take their ramifications from secondary channels which in turn originating from main channel. The water flows from the reservoir intake into the main canal which folks into two main channels before entering the secondary canals (the left hand secondary canal and the right hand secondary canal).

\subsection{Identification of Farmers}

Water users of Kanyonyomba rice irrigation perimeter are grouped in Rice Farmers Cooperative of Marsh Kanyonyomba (CORIMAK) which was created in 2003, and recognized by the Ministry of Commerce (MINICOM) in 2005. Some of water users come from nearby community while others come from elsewhere. Everyone has at least one plot in the swamp.

\subsubsection{Distribution of Respondents in Relation to Gender}

Both men and women practice irrigation in the Kanyonyomba swamp. Their proportions are materialized in Table 1 below.

The presence in the majority of the male gender (61\%) and the minority of the females can be explained by the facts that the art of growing rice is new in this region as well as the cost of growing rice until its harvesting. It requires extra effort that can mostly be provided by men. Besides this, most of the Kanyonyomba rice farmers from other regions are men.

\subsubsection{Marital Status of Respondents}

Marital status of rice farmers practicing irrigation in Kanyonyomba swamp is shown in Table 2 below.

As indicated in Table 2, the majority of rice farmers in Kanyonyomba swamp are single (50\%). This shows that young people are more dynamic and even the art of growing rice is new in this region.

\subsubsection{Level of the Study of Respondents}

The level of education of respondents taken randomly from rice farmers in Kanyonyomba rice perimeter is presented in Table 3.

The majority of farmers practicing rice cultivation in the Kanyonyomba swamp are educated as 50\% in primary and $28 \%$ in secondary levels. We also noted that there are a lot of illiterate rice farmers (22\%).

Table 1. Gender of respondents.

\begin{tabular}{ccc}
\hline Gender & Effective & Percentage \\
\hline Males & 22 & 61 \\
Females & 14 & 39 \\
Total & 36 & 100 \\
\hline
\end{tabular}

Table 2. Marital status of respondents.

\begin{tabular}{ccc}
\hline Marital status & Effective & Percentage \\
Single & 18 & 50 \\
Married & 14 & 38.9 \\
Widow (er) & 4 & 11.1 \\
Total & 36 & 100 \\
\hline
\end{tabular}




\subsection{Public Awareness on the Use of Irrigation System in Kanyonyomba Rice Perimeter}

The majority of rice farmers in Kanyonyomba swamp participated in meetings organized prior to the implementation of the irrigation system. Those who did not participate in these meetings are those who came after the project implementation, or who do not originate nearby the region. Table 4 below indicates various levels for public awareness for the list of items selected.

Among the respondents, those who were absent during the sensitization on the use of irrigation system were not concerned with certain questions. Therefore, the total effective of respondents changed from thirty six to thirty. According to Table 4, it was noted that the topic that came mostly during the public awareness about the use and role of the new implemented irrigation system was the increase of agricultural production (33\%). Technical innovation in agriculture and the increase of rice production also occupied a significant place (27\%). Outreach meetings also spoke about the fight against poverty, but not very frequently (13\%). These themes were often animated by the district agronomists or supervisors of the project in consultation with representatives of the administration.

\subsection{The Effects of the Irrigation System on the Biological Environment}

Table 5 gives the information about Kanyonyomba marsh users before the implementation of irrigation system.

According to Table 5, it appears that 33\% of the farmers were already working in the swamp. This means that the irrigation system has the effect of increasing the number of marsh users in the swamp. Thus, irrigation system in this marsh has the effects of concentrating and intensifying production on a smaller area resulting in the protection of forests or wild lands from being converted to agriculture [4].

Respondents told us that all the swamp was not exploited before the implementation of irrigation system. Exploited part of the marshland of Kanyonyomba was characterized by mixed farming while the unexploited part was undrained marshland with a typical savanna vegetation dominated by papyrus species of grasses and several

Table 3. Study level of respondents.

\begin{tabular}{ccc} 
Level & Effective & Percentage \\
Illiterates & 8 & 22.2 \\
Primary education & 18 & 50 \\
Secondary education & 10 & 27.8 \\
Total & 36 & 100 \\
\hline
\end{tabular}

Table 4. Public awareness on the use of irrigation system.

\begin{tabular}{ccc}
\hline Awareness themes & Effective & Percentage \\
\hline Increase of agriculture production & 10 & 33 \\
Technical innovation in agriculture & 8 & 27 \\
Increase of rice production & 8 & 13 \\
Poverty reduction & 4 & 100 \\
Total & 30 & 27 \\
\hline
\end{tabular}

Table 5. Marsh users before implementation of irrigation system.

\begin{tabular}{ccc}
\hline Marsh users & Effective & Percentage \\
\hline Yes & 12 & 33 \\
No & 24 & 67 \\
Total & 36 & 100 \\
\hline
\end{tabular}


species of birds. There was an increase of space for agriculture and the disappearance of plant and animal species as having no shelter, no food and no support. There was also proliferation of other species including fish of the genus clarias in the reservoir, the birds eating rice, birds forage on the ground, and some rodents. In addition, there are a few mosquito larvae along the river banks.

\subsection{The Effects of Irrigation System on the Physical Environment}

\subsubsection{Effects of Irrigation System on the Soil}

Table 6 below represents the synthesis analysis of acidity and soil salinity.

The observations from Table 6 show that the $\mathrm{pH}$ of the soil (whether it is the $\mathrm{pH}$ in water or $\mathrm{KCl}$ ) is slightly higher in the second layer than in others. This means that the second layer is slightly less acid compared to the other two. However, compared to the $\mathrm{pH}$ interpretation of standards [10] (Table 7), we find that the soil is slightly acidic because it has a $\mathrm{pH}$ ranging between 5.2 and 6.2 for results obtained using the $\mathrm{pH}$ meter with water and 5.0 - 6.0 for that with $\mathrm{KCl}$. Thus, the final $\mathrm{pH}$ (5.60 and 5.36) also endorsed this statement.

The analysis of electric conductivity shows the same behavior as that of $\mathrm{pH}$ in the various layers. The 20 - 40 $\mathrm{cm}$ has a higher electrical conductivity of 107.85 microseconds/cm compared to the remaining 0 - 20 and 40 - 60 cm layers with $104.15 \mu \mathrm{s} / \mathrm{cm}$ and $101.30 \mu \mathrm{s} / \mathrm{cm}$ respectively although the difference is not important. This provides information on soil salinity which is a bit higher in this layer. After comparing our results with the salinity risk standards shown in the Table 8 below, we found that the soil was at low risk because of low salinity with an average salinity of 104.4 microseconds/cm compared to the medium risk limits of soil salinity whose positive ions exchange capacity ranges between $250 \mu \mathrm{s} / \mathrm{cm}$ and $750 \mu \mathrm{s} / \mathrm{cm}$ [11]. The increase in acidity and salinity in the second layer is an information about the migration of ions from the water accumulated on the surface of the soil. Further salts gradually leave the surface layer to form a deposit in the deeper layer.

\subsubsection{Effects of Irrigation System on Water}

The synthesis of the analysis of water acidity and salinity is presented with Table 9 .

Table 6. Summary of the analysis of acidity and soil salinity.

\begin{tabular}{cccc}
\hline Layer (cm) & $\mathbf{p H}($ water) & $\mathbf{p H}(\mathbf{K C l})$ & Electrical conductivity $(\boldsymbol{\mu S} / \mathbf{c m})$ at $\mathbf{2 4}^{\circ} \mathbf{C}$ \\
\hline $0-20$ & 5.60 & 5.32 & 104.15 \\
$20-40$ & 5.64 & 5.40 & 107.85 \\
$40-60$ & 5.58 & 5.37 & 101.30 \\
Average & 5.60 & 5.36 & 104.40 \\
\hline
\end{tabular}

Table 7. pH interpretation standards with water and with $\mathrm{KCl}[10]$.

\begin{tabular}{ccccccc}
\hline pH & FO.AC & T.AC & MO.AC & FA.AC & NEUT & FA.BA \\
\hline pH with water & $3.5-4.2$ & $4.2-5.2$ & $5.2-6.2$ & $6.2-6.9$ & $6.9-7.6$ & $7.6-8.5$ \\
pH with KCl & $3.0-4.0$ & $4.0-5.0$ & $5.0-6.0$ & $6.0-6.8$ & $6.8-7.2$ & $7.2-8.0$ \\
\hline
\end{tabular}

Where: FA.AC: range of a very less acidic water; FA.BA: range of a very less basic water; FO.AC: range of a very high acidic water; T.AC: range of a totally acidic water; MO.AC: Average range of an acidic water; NEUT: Water at its neutral state.

Table 8. Risk of soil salinity [11].

\begin{tabular}{|c|c|}
\hline Electric conductivity $\left(\mathrm{EC}\right.$ at $\left.25^{\circ} \mathrm{C}\right) \mu \mathrm{S} / \mathrm{cm}$ & Observations \\
\hline $\mathrm{EC} \leq 250$ & Low risk \\
\hline $250<\mathrm{EC} \leq 750$ & Medium risk \\
\hline $750<\mathrm{EC} \leq 2250$ & High risk \\
\hline$E>2250$ & Very high risk \\
\hline
\end{tabular}


The results in Table 9 show that the $\mathrm{pH}$ of water is raised at the inlet (7.12) and decreased in the irrigated perimeter (6.73) and then increases slightly towards the outlet of irrigated perimeter (6.85). By referring to Table 7 showing the $\mathrm{pH}$ interpretation standards, water was found to be neutral at the inlet (6.9 - 7.6), slightly acid in the perimeter and outlet of it. This would be due to the use of fertilizers and pesticides. For water salinity, we found that the results interpretations are similar to those for the $\mathrm{pH}$. This means that the salinity is high at the inlet of the irrigated perimeter with a value of $465 \mu \mathrm{s} / \mathrm{cm}$, low in the irrigated perimeter with a value of $317.5 \mu \mathrm{s} / \mathrm{cm}$ and increases to $355 \mu \mathrm{s} / \mathrm{cm}$ at the outlet of the irrigated perimeter. Compared to the World Health Organization (WHO) standards, for the salinity range of $250 \mu \mathrm{s} / \mathrm{cm}$ to $750 \mu \mathrm{s} / \mathrm{cm}$, the risk is said to be medium. In terms of our study, the salinity of our three sampling points is showing a medium risk, because the values are between the limits of the tolerable margin, Table 8.

\subsubsection{Analysis of the Presence of Certain Ions}

The Analysis of the presence of certain ions was synthesized in Table 10 below.

The results of the analysis presented in Table 10 show the presence of $\mathrm{SO}_{4}{ }^{2-}, \mathrm{NO}_{3}{ }^{-}$ions and heavy metals such as $\mathrm{Pb}, \mathrm{Cd}$ and $\mathrm{Cr}$. The high concentration of sulfate and nitrate ions at the perimeter and outlet levels is associated with agricultural inputs added in irrigating the perimeter such as nitrogen fertilizers and some pesticides. As shown in Table 10, we have not been able to detect the presence of phosphate ions. According to our survey, fertilizers containing phosphates are not used in this environment up to now. Note also that our respondents complain the effects of using urea as fertilizer to increase the vegetative part of rice (foliage) while its main contribution should be to increase the yield of the crop (seeds).

The concentration of $\mathrm{Pb}, \mathrm{Cd}$ and $\mathrm{Cr}$ is high at the intake as well as at the exit of the irrigated perimeter. This would mean that these elements are already present in irrigation water. Compared to the standards of the World Health Organization (WHO) regarding $\mathrm{Pb}$, an average of $6.0 \mathrm{ppm}$ is ranging in the tolerable margin set from 5 to $1000 \mathrm{ppm}$. It is the same for Cd for which we found $0.33 \mathrm{ppm}$ while the acceptable margin is in the range of 0.01 to $0.70 \mathrm{ppm}$. Regarding Cr, in connection with our results in Table 10, a value of $0.23 \mathrm{ppm}$ is less than the minimum acceptable value of 5 ppm set by the WHO as shown in Table 11 below [10].

Table 9. Summary of the analysis of water acidity and salinity.

\begin{tabular}{ccc}
\hline Sample locations & $\mathbf{p H}$ & Conductivity $(\boldsymbol{\mu S} / \mathbf{c m})$ at $\mathbf{2 2}^{\circ} \mathbf{C}$ \\
\hline Intake level & 7.12 & 465.00 \\
Irrigated perimeter level & 6.73 & 317.50 \\
Outlet level & 6.85 & 355.00 \\
Average & 6.90 & 379.19 \\
\hline
\end{tabular}

Table 10. Summary of the analysis of certain ions.

\begin{tabular}{ccccccc}
\hline Sample location & $\mathbf{P O}_{4}{ }^{3-} \mathbf{( p p m )}$ & $\mathbf{S O}_{4}{ }^{2-} \mathbf{( p p m )}$ & $\mathbf{N O}_{3}{ }^{-} \mathbf{( p p m )}$ & $\mathbf{P b}(\mathbf{p p m})$ & $\mathbf{C d}(\mathbf{p p m})$ & $\mathbf{C r}(\mathbf{p p m})$ \\
\hline At the intake level & - & 16.00 & 1.09 & 10.20 & 0.59 & 0.53 \\
At irrigated perimeter level & - & 16.50 & 1.49 & 4.20 & 0.21 & 0.10 \\
At the outlet of the perimeter & - & 12.70 & 1.28 & 3.60 & 0.21 & 0.10 \\
Average & - & 15.00 & 1.28 & 6.00 & 0.33 & 0.243 \\
\hline
\end{tabular}

Table 11. Standard values for the interpretation of the content of some heavy metals in ppm.

\begin{tabular}{|c|c|c|}
\hline Heavy metals & Average & Range \\
\hline Cadmium (Cd) & 5 & $0.01-0.70$ \\
\hline Copper (Cu) & 20 & $2-100$ \\
\hline Chromium (Cr) & 200 & $5-1000$ \\
\hline Lead (Pb) & 10 & $2-200$ \\
\hline Zinc (Zn) & 50 & $1-300$ \\
\hline
\end{tabular}




\subsection{Effects of Irrigation System on the Social Aspect Views}

Respondents testified that they continue to grow in the marsh but the dimensions of the plots that they had before the implementation of irrigation system are no longer the same. Some of rice workers do not have plots in the swamp while they came in searching the plots after the implementation of the irrigation system in order to produce rice. Special cases are observed where cows near the irrigated perimeter cause destruction and blockage of channels. Table 12 below gives an information about the presence of diseases that attack the rice crop.

As shown in Table 12, among 36 people surveyed, 78\% confirm the presence of diseases that attack rice. Those diseases are manifested by wilting of rice crop, dwarfism and reddish color, the right of succession to insect attack and the lack of fruiting. Pesticides are granted by CORIMAK farmers cooperative.

\subsection{Effects of Irrigation System on Agricultural Production}

During survey, all respondents agreed that the rice was not cultivated in the Kanyonyomba swamp before the dam construction in 2005. Actually, there is no rotation with other crops. So there have been changes in the habits of farmers of Kanyonyomba marsh. Mixed farming was replaced by rice monoculture and selected seeds and fertilizers are provided by the CORIMAK. Thus, there is no longer the problem of lacking selected seeds and fertilizers during farming season. According to the surveyed persons, the fertilizer used is urea. The problem they have with this fertilizer is that the rice develops a lot of leaves and all farmers would have NPK fertilizer instead of urea. Table 13 is explaining the estimated contribution of the cultivation of rice in the marsh of Kanyonyomba

Table 13 reveals that rice farmers in Kanyonyomba marsh do not get benefit from irrigation system. They say that the costs of labor and maintenance are so expensive. However, they continue to practice rice cultivation because they do not want to buy it at the market at harvesting time given the limited means they have. In addition, they hope that the production will rise as the time goes on even if climatic factors influence the production.

\subsection{Effects of Irrigation System on Population Health}

According to our survey, the number of victims into the dam reservoir is about 10 people. The victims are composed mostly with children who try to swim in the reservoir. The cooperative CORIMAK should draw strict preventives measures to these water accidents. Besides these dam reservoir accidents, Table 14 below shows the number of people who drink water from the reservoir.

Table 12. Presence of diseases that attack rice crop.

\begin{tabular}{ccc}
\hline Diseases & Effective & Percentage \\
\hline Yes & 28 & 88 \\
No & 8 & 22 \\
Total & 36 & 100 \\
\hline
\end{tabular}

Table 13. Estimated intake of rice cultivation.

\begin{tabular}{ccc}
\hline Estimation & Effective & Percentage \\
\hline Gain & 12 & 33 \\
Loss & 24 & 67 \\
Total & 36 & 100 \\
\hline
\end{tabular}

Table 14. Estimated number of those who drink water from the dam reservoir.

\begin{tabular}{ccc}
\hline Dam water users & Effective & Percentage \\
\hline Yes & 24 & 67 \\
No & 12 & 33 \\
Total & 36 & 100 \\
\hline
\end{tabular}


As shown in Table 14, respondents said that before the implementation of irrigation system, they drank water from the Kanyonyomba River. After the construction of the earth dam, a lot of people equal to $67 \%$ continue to drink this water. The most common diseases in this environment are malaria, influenza, cough, ventral disorders and diarrhea. According to the respondents, these diseases exist from many years ago except that today they become very pronounced. So, irrigation system has impacted on the Kanyonyomba River as a drinking water supply and on the proliferation of water diseases due to dam reservoir. Again here the cooperative CORIMAK and the local authorities should take the responsibility to mitigate this issue of potable water. The only $33 \%$ who are fetching potable water in their environment are located away from the Kanyonyomba dam reservoir.

\subsection{The Proposed Monitoring Plan for the Proper Management of Kanyonyomba Swamp}

The proposed monitoring plan for the proper management of Kanyonyomba rice perimeter should be based on the identified impacts and their mitigation measures as summarized in the Table 15 below.

\section{Concluding Remarks}

By concluding this work, it is necessary to look back on the results of our research. In order to understand the environmental impact of an irrigation system, analyses of water and soil were carried out in the laboratory; many surveys and observations were carried out at the field. The introduction of the irrigation system was not a matter of chance in the swamp of Kanyonyomba. The population was prepared in advance with awareness meetings about predominant themes such as on increased agriculture production, technical innovation in agriculture, increased rice production and poverty reduction.

After surveys, observations and various laboratory tests on water and soil, we found that this irrigation system has positive and negative effects on the studied area. Among positive impacts includes the increase in agricultural production thereby ensuring food security which results in poverty and hunger reduction. The research also found that the introduction of irrigation system attracted large number of farmers in the swamp of Kanyonyomba resulting to the reduction of pressure on land in the region. Thus, the concentration and intensification of production brought by irrigation on a smaller area can protect forests or wild lands from being converted to agriculture. The reservoir formation in this area for irrigation purpose has also brought new genus clarias fish species.

Regarding the negative impacts, the irrigation system has created several changes in the host environment. Among them, biological changes include the destruction of the existing fauna and flora. With regard to the physical environment changes, irrigated area is regularly submerged which implies the presence of micro-organisms responsible for diseases. After the analysis of soil, we found that the marsh of Kanyonyomba is mildly

Table 15. Proposed impacts and their mitigation measures.

\begin{tabular}{|c|c|}
\hline Identified impacts & Mitigation measures \\
\hline Soil acidity & Regularly application of lime \\
\hline \multirow{4}{*}{ Threats to the health of farmers } & Provision of boots and gloves that reduces the contact of farmer with mud \\
\hline & Preventing the accidents by fencing the dam reservoir \\
\hline & Build a health center nearby the area \\
\hline & Provide safe drinking water to the community \\
\hline Disturbance of the natural environment & Revegetation and restoration of animal species \\
\hline Congestion in regular water irrigation scheme & Regular cleaning of irrigation and drainage channels \\
\hline \multirow{2}{*}{ Erosion and Sedimentation in the reservoir } & $\begin{array}{l}\text { Construction of anti-erosive ditches along the dam reservoir and other } \\
\text { watershed management measures }\end{array}$ \\
\hline & Also regular reservoir dredging can be required \\
\hline $\begin{array}{c}\text { Wastage of time to prevent birds from undermining rice } \\
\text { during the fruiting phase }\end{array}$ & Install automatic devices to prevent birds from undermining rice \\
\hline
\end{tabular}


acidic with a $\mathrm{pH}$ of 5.36 where analysis of ions and heavy metals identifies the presence of $\mathrm{SO}_{4}{ }^{2-}, \mathrm{NO}_{3}{ }^{-}$ions and heavy metals such as $\mathrm{Pb}, \mathrm{Cd}$ and $\mathrm{Cr}$ with high concentration of sulfate and nitrate ions in the perimeter and outlet levels as a result of agricultural inputs added in the irrigated perimeter such as nitrogen fertilizers and some pesticides. The high concentration of these ions at the outlet of the irrigation system leads to the deterioration of water quality below an irrigation project which can render the water unfit for other users and harmful to aquatic species. The high nutrients content results in aquatic weed growth that clogs waterways and has health and ecological consequences.

We also found that the concentration of $\mathrm{Pb}, \mathrm{Cd}$ and $\mathrm{Cr}$ is high at the intake as well as at the exit of the irrigated perimeter which explains the presence of those elements in irrigation water. Compared to the WHO standards regarding $\mathrm{Pb}$, the average of our results shows that the value found of $6.0 \mathrm{ppm}$ is ranging in the tolerable margin set from 5 to $1000 \mathrm{ppm}$. It is the same for $\mathrm{Cd}$ for which we found $0.33 \mathrm{ppm}$ while the acceptable margin is in the range of 0.01 to $0.70 \mathrm{ppm}$. Regarding $\mathrm{Cr}$, in connection with our results, its value of $0.23 \mathrm{ppm}$ is less than the minimum acceptable value of 5 ppm set by the WHO.

Among the principal identified adverse impacts, soil acidity, threats to the health of farmers, disturbance of the natural environment and erosion and sedimentation in the reservoir. Hence, their mitigation measures such as regular application of lime, reduction of the accidents by fencing the reservoir, building a health center in the vicinity of the area, providing safe drinking water to the community and a provision of boots and gloves to reduce the contact of farmers with mud and construction of sediment retaining channel along the dam reservoir and watershed management measures should be implemented so as to mitigate negative impacts of the rice irrigation perimeter.

\section{Acknowledgements}

The work reported here was undertaken as a part of a project carried out by the University of Rwanda (UR), School of Engineering and the School of Education. The authors wish to acknowledge the support of Government of Rwanda, through Student Funding Agency of Rwanda (SFAR). The authors also express sincere gratitude to the governmental agencies such as Rwanda Natural Resources Authority and Ministry of Agriculture and Animal resources that provided all data used in this study. Finally, our thanks go to Eng. Jean D’Amour Uwimana Shumbusho who accepted to publish with us some of his Post Graduate Diploma research results.

\section{References}

[1] MINAGRI (2008) Rapport Final: Stratégie de Développement de l’Irrigation en Marais. Projet d’Appui au Secteur Rural (PASR). Rwanda, 117 p.

[2] Ray, S.K., Hanumantha, C., Rao, H. and Subbarao, K. (1988) Unstable Agriculture and Droughts: Implications for Policy. Studies in Economic Development and Planning, 47. General Editor: T.N. Madan. Institute of Economic Growth, New Delh.

[3] FAO (2000) Implementation Completion Report, Indonesia. Groundwater Development Project (Draft). Loan 3588-IND. Confidential Report No. 00/006 CP-INS. FAO/World Bank Co-Operative Programme, Rome, 4 February 2000.

[4] Dhawan, B.D. (1988) Irrigation in India’s Agricultural Development: Productivity, Stability, Equity. Institute of Economic Growth, Sage Publications, Delhi.

[5] Kerr, J. and Kohlaralli (1999) Methodological Issues in Assessing the Impact of Agricultural Research on Poverty Alleviation. In: Impact of Agricultural Research on Poverty Alleviation. Conceptual Framework with Illustrations from the Literature. EPTD. DP56.

[6] Carruthers, I., Rosegrant, M.W. and Seckler, D. (1997) Irrigation and Food Security in the 21st Century. Irrigation and Drainage Systems, 11, 83-101. http://dx.doi.org/10.1023/A:1005751232728

[7] Ingénieur, HYDROPLAN (2002) Etude du Schéma Directeur d’Aménagement des Marais, de Protection des Bassins Versants et de la Conservation des Sols. Rapport Global Définitif Phase 1, Kigali, 41 p.

[8] MINITERE (2007) Sélection d'un Consultant Individuel pour l'Etude Environnementale et Sociale Stratégique. Kigali.

[9] D’Haese, L., et al. (1985) Etude multidisciplinaire des Systèmes d’Exploitation Agricole dans la Région d'Ijenda. Phase Descriptive, Tome1, Université du Burundi (UB), Faculté d’Agronomie (FACAGRO), 269 p.

[10] Chassin, P., et al. (1996) Les éléments Traces Métalliques et la Qualité des Sols. Impacts en Moyen et à Long Terme. Forum “Le Sol, un Patrimoine Menacé?”. Paris, 24 Octobre 1996.

[11] Mermoud, A. (2006) Aménagement et Equipement du Territoire. s.l.: Ecole Polytechnique Fédérale de Lausanne. 